\section{AATS Around the World}

There are a number of AATS postgraduate courses that take place in connection to the annual meetings of other thoracic surgery organizations. Here are the upcoming AATS postgraduate courses:

\section{AATS Postgraduate Course at IACTS}

Ahmedabad, Gujarat, India

February 6, 2020

\section{Program Director:}

Marc R. Moon

\section{Local Program Directors:}

Shiv K. Nair

Dhaval Naik

\section{AATS Postgraduate Course at ASCVTS \\ Chiang Mai, Thailand \\ February 7, 2020}

\section{Program Directors:}

Emile Bacha

David Jones

Marc Moon

\section{Local Program Director:}

Taweesak Chotivatanapong

\section{View Updated Content on AATS Online}

You can now view presentations from the 2019 International Thoracic Surgical Oncology Summit on AATS Online. Access any of the presentations from the two-day meeting via the button below or go to AATS Online in the top navigation menu on the AATS Web site and select on Presentations from the drop-down menu. You will be prompted to $\log$ in and can use the available links if you do not know your user name and password.

To see the presentations from the Thoracic Summit or any other meeting, use the filter on the left side of the Presentation page to select the meeting from the drop-down menu and set the year. Refine your search further by using the search box to look for specific topics or presenters.

You can also search for other content on AATS Online including surgical videos, images, guidelines, and discussions with experts.

\section{Update Your AATS Profile}

Check that the information in your aats.org profile is current to ensure that you are receiving AATS information that is most important to you. By updating your contact information and sharing your areas of interest, you will be able to optimize your use of AATS Online and receive relevant AATS news. While you are in your profile, you can upload a recent photo, view your AATS activity, and more. To access your profile, log in using the "Sign In" or "My Account" link at the top of aats.org.

\section{The AATS Foundation}

\section{Supporting the Future

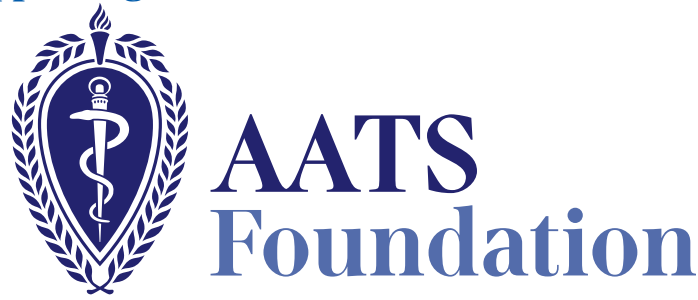

Generous donors and partners ensured that 2019 ended on a positive note by contributing to the AATS Foundation's end-of-year Annual Appeal. Many individuals took advantage of the AATS matching grant by making contributions of $\$ 5,000$ or more. Foundation leadership will be sharing the results of the campaign in the coming weeks.

Donor support will profoundly impact individual surgical scholarship, advance patient-care in cardiothoracic surgery around the world and enhance the mission of supporting cardiothoracic surgeons in research and education.
The philanthropic arm of the American Association for Thoracic Surgery will continue to foster careers and develop leaders in 2020. In the coming months, there will be

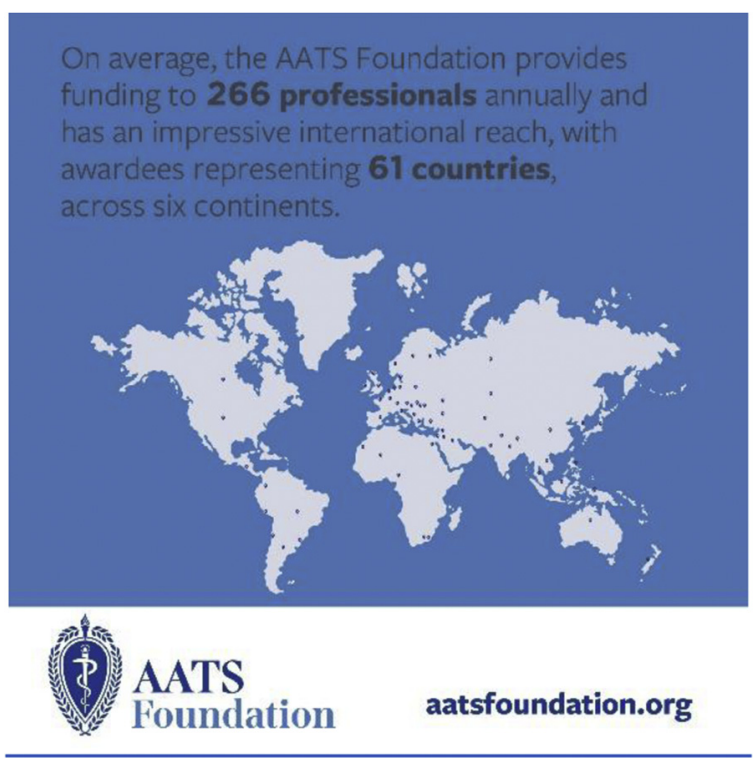

